\title{
Employees' Job Characteristics and Job Crafting Behavior: The Mediating Role of Perceived Opportunities to Craft
}

\author{
Dr. Jessica van Wingerden MBA MCC (Corresponding author) \\ Schouten Global, Centre of Research, Knowledge and Innovation, \\ P.O. Box 266, 5300 AG Zaltbommel, The Netherlands
}

Prof. dr. Rob Poell

Dept. of Human Resource Studies, Tilburg University, The Netherlands

PO Box 90153, 5000 LE, Tilburg, The Netherlands

Received: Aug. 27, 2018 Accepted: Sep. 21, 2018 Online published: Oct. 11, 2018

doi:10.5296/ijhrs.v8i4.13764

URL: https://doi.org/10.5296/ijhrs.v8i4.13764

\begin{abstract}
The present study was designed to gain knowledge about the relationship between job characteristics in the workplace (job demands and job resources), employees' perceived opportunities to craft, and subsequently their actual job crafting behavior. Specifically, the potential mediating role of perceived opportunities to craft could shed better light on the mechanisms that lead employees to job craft in the context of particular work characteristics. We collected data among a group of Dutch health care professionals working in an organization that offers care for patient with mental disabilities $(N=522)$. Participants of the study reported their job demands; workload, emotional demands and work-home interference, their job resources; role clarity, communication and team cohesion, their perceived opportunities to craft, and their job crafting behavior. We tested the hypothesized antecedents of job crafting perceptions and behavior model with structural equation modelling (SEM) analyses. Results indicated that perceived opportunities to craft mediates the relationship between job resources and employees actual job crafting behavior. The insights provided in this study do not only build on job crafting literature but are also helpful to understand which aspects of the workplace influence employees' job crafting behavior. Therefore, these insights may be useful for the deliberate cultivation of job crafting behavior within organizations.
\end{abstract}

Keywords: job demands, job resources, perceived opportunities to craft, job crafting, health 
care

\section{Introduction}

In today's volatile, uncertain, complex, and ambiguous world, work and the way work is done has changed significantly in different sectors all over the world (Bennett \& Lemoine, 2014; Grant \& Parker, 2009; World Economic Forum, 2016). In Western society, health care organizations are facing challenges in the realms of heightened public expectations, rising costs, technological advances and demographic changes (Randall \& Williams, 2006). Health care organizations that want to be responsive to change must constantly reinvent themselves, facilitate new ways of working and stimulate employees' reskilling (Cooke \& Bartram, 2015; van Stenis, van Wingerden, \& Kolkhuis Tanke, 2017; Yeatts \& Cready, 2007; World Economic Forum, 2017). The complexity of work in health care has increased considerably due to organizational innovations, such as agile working and self-managing teams (Lusky \& Ingman, 1994; Wageman, 2001; Yeatts, Cready, Ray, DeWitt, \& Queen, 2004). Within these changing work environments, there is a need for employees to be proactive and take their own responsibility to stay connected to their job. Employees can proactively optimize the fit between their (changing) job and their personal skills, talents, and interests through job crafting. By crafting their job, employees proactively adapt different aspects of their job, such as their job tasks, relations at work and cognitions about work (Wrzesniewski \& Dutton, 2001). Different studies have revealed that this type of proactive employee behavior has several benefits related to employee' well-being and organizational performance (Bakker, Tims, \& Derks, 2012; van Wingerden, Bakker, \& Derks, 2017a; van Wingerden, Bakker, \& Derks, 2017b). These benefits of employees' job crafting behavior make job crafting a topic of interest for both business and science.

Whether or not employees will proactively craft their job, may depend on different factors related to their work environment (van Wingerden \& Niks, 2017; van Wingerden \& Poell, 2017; Wrzesniewski, 2003; Wrzesniewski \& Dutton, 2001). Different studies suggest that employees' actual job crafting behavior in the workplace may depend on job characteristics, such as job demands and job resources (Berg et al., 2010; Ghitulescu, 2007; Lyons, 2008; van Wingerden \& Niks, 2017; van Wingerden, Derks, Bakker, \& Dorenbosch, 2013; Wrzesniewski, 2003; Wrzesniewski \& Dutton, 2001). In addition, recent literature suggests that job demands and job resources may be antecedents of employees' perceived opportunities to craft, which in turn is related to actual job crafting behavior (van Wingerden \& Poell, 2017). Therefore, not only does job crafting have the potential to change job characteristics (job demands and job resources) but the intention to craft one's job (and, subsequently, job crafting behavior) may also be encouraged or discouraged by current job characteristics. Hence, the central aim of the present study is to examine the proposed relationship between job characteristics in the workplace (job demands and job resources), employees' perceived opportunities to craft, and subsequently their actual job crafting behavior. Specifically, the potential mediating role of perceived opportunities to craft could shed better light on the mechanisms that lead employees to job craft in the context of particular work characteristics. 


\section{Theoretical Background}

\subsection{Workplace Characteristics: A Job Demands-Resources Theory Approach}

In contemporary workplaces, employees work in a variety of jobs from which they contribute to their organization's goals. Jobs differ with respect to the skills, knowledge and capabilities employees need to meet their work-related goals. Where a welder depends on his or her craftsmanship and uses physical strengths at work, a health care professional needs to be empathetic and use her or his specific health care skills. In a similar vein, the workplaces of the welder and the health care professional may look very different. Although jobs and workplaces may be different in many ways, they also have an important similarity according to Job Demands-Resources (JD-R) Theory (Bakker \& Demerouti, 2014). JD-R Theory states that every job and workplace is characterized by job demands (aspects of the job that require energy) and job resources (aspects of the job that give energy).

Job demands are "the physical, social or organizational aspects of the job that require physical and/or cognitive engagement and that are associated with physical and psychological costs; job resources are those aspects of the job that help employees to achieve their work goals" (Demerouti, Bakker, de Jonge, Janssen, \& Schaufeli, 2001, p. 501). Job demands that are typically found in the field of health care are a high workload, encountering situations that are emotionally demanding and work-home interference (Gaillard, 2006; Homburg, van der Heijden, \& Valkenburg, 2013). Job demands can be challenging, but when meeting those demands requires a major effort from employees, they may turn into job stressors (Bakker \& Demerouti, 2014). The other type of job characteristics, job resources, are those aspects of the job that are functional in achieving work goals and can reduce job demands and the associated costs (Demerouti et al., 2001). Besides buffering the impact of job demands, job resources can also stimulate personal growth and development.

In the past two decades, health care has become more demand-driven and customized to the wishes of the clients (Rijckmans, Garretsen, Goor, \& Bongers, 2006). To meet client expectations in relation to more diverse and flexible care, health care organizations have implemented self-managing teams (Molleman, Nauta, \& Jehn, 2004; van der Vegt, Bunderson, \& Kuipers, 2010). To reach their work-related goals and offer diverse, flexible and high-quality care, health care professionals need an adequate amount of resources (French, Ikenwilo, \& Scott, 2007). Within self-managing teams, resources such as role clarity, communication and team cohesion are crucial for optimal functioning and team effectiveness (Mathieu, Maynard, Rapp, \& Gilson, 2008). For example, relationships between the team members, clarity about roles and open communication within the team are crucial in ad-hoc decision making regarding flexible care and in reaching consensus regarding issues in the workplace (Beal et al., 2003; Hobman, 2004). Research among health care professionals revealed that the job resources role clarity, communication and team cohesion are needed for optimal functioning within the field of health care (Atefin, Abdullah, Wong, \& Mazlom, 2014; Nei, Snyder, \& Litwiller, 2015; Simpson, 2009; Valentine et al., 2015).

Job demands and resources may be influenced by clients and employers. For example, clients can give health care professionals compliments for their work or show them their gratitude 
(job resources), but at the same time clients can also be very demanding or may even become aggressive (job demands). In a similar vein, supervisors can give their employees opportunities for professional development and/or influence in decision-making processes (job resources), but at the same time supervisors can also confront their employees with high workload and numerous deadlines (job demands). Job demands and job resources can also be adapted by employees themselves. This bottom-up adaptation of job demands and job resources by employees is also known as job crafting.

\subsection{Job Crafting: Self-Initiated Change Behaviors in the Workplace}

The concept of job crafting originates from the start of the twenty-first century, when Wrzesniewski and Dutton (2001) published the article "Crafting a job: Revisioning employees as active crafters of their work". Over the last seventeen years, job crafting has gained much interest among researchers and managers from all over the world. Job crafting can be defined as "the changes employees may make to balance their job demands and job resources with their personal abilities and needs" (Tims, Bakker, \& Derks, 2012, p. 174). Tims, Bakker, and Derks (2012) operationalized job crafting behavior - the proactive adaptation of job characteristics - in line with Job Demands-Resources (JD-R) Theory (Bakker \& Demerouti, 2014). According to the JD-R approach of job crafting, employees can craft their job by adapting their job demands and job resources from four perspectives; 1 . increasing their social job resources, 2. increasing structural job resources, 3. increasing challenging job demands and 4. decreasing hindering job demands (Tims et al., 2012). The fourth dimension of job crafting (decreasing hindering job demands) will not be included in the current study, since earlier studies have shown ambiguous results of decreasing hindering job demands (Petrou, Demerouti, Peeters, Schaufeli, \& Hetland, 2012; Tims, Bakker, Derks, \& van Rhenen, 2013; van Wingerden, Bakker, \& Derks, 2017c).

Proactive changes that employees make in their job may result in permanent changes in their job design (LePine \& Van Dyne, 1998). Thus, by crafting their job, employees proactively influence their job characteristics and the design of their job. According to JD-R theory (Bakker \& Demerouti, 2014), employees who actively redesign their jobs and work environment through job crafting are seeking to acquire job resources that may help them better cope with their job demands and achieve their work goals. Job crafting behavior in the workplace is important because it may lead to several positive outcomes for both employees and employers. Research revealed that employees who balance their job demands and job resources with their personal abilities and preferences experience less stress, better well-being (Slemp \& Vella-Brodrick, 2014), and less work-home conflict (Akkermans \& Tims, 2017). In addition, job crafting is also known to contribute to employees' experience of meaningful work, career success (Cenciotti, Alessandri, \& Borgogni, 2017; Wellman \& Spreitzer, 2011; Wrzesniewski, LoBuglio, Dutton, \& Berg, 2013; Akkermans \& Tims, 2017), employability (Petrou et al., 2012), organizational commitment (Ghitulescu, 2007) and it has been associated with readiness to change (Lyons, 2008). Further, research has revealed that job crafting is a predictor of work engagement (Bakker, Tims, \& Derks, 2012; van Wingerden, Bakker, \& Derks, 2017a), basic needs satisfaction (van Wingerden, Bakker, \& Derks, 2017a), as well as task and contextual performance on the job (Demerouti, Bakker, \& Gevers, 2015; 
Leana, Appelbaum, \& Shevchuk, 2009; van Wingerden, Bakker, \& Derks, 2017b).

\subsection{To Craft or not to Craft, That's the Question}

Although the concept of job crafting may be appealing to contemporary employees and organizations, it is not self-evident that every employee will proactively craft her or his job. Whether or not employees will make self-initiated changes aimed at aligning their job (and work environments) with their own preferences, motives, and passions, may depend on employees' perceived opportunities to craft (van Wingerden \& Niks, 2017; van Wingerden \& Poell, 2017; Wrzesniewski, 2003; Wrzesniewski \& Dutton, 2001). Perceived opportunities to craft can be defined as employees' perceptions regarding their opportunities to proactively optimize their own work environment (van Wingerden \& Poell, 2017). Employees' perceived opportunity to craft may be influenced by different factors such as the work environment, organizational climate and management behavior.

Our assumption that employees' perceived opportunities to craft may determine whether they will craft their jobs was supported by a qualitative study among teachers who participated in a job crafting training (van Wingerden et al., 2013). Participants of the job crafting training who reported that they did not perceive opportunities to craft their job stated that they did not succeed in crafting their job during and/or after the training program. These participants felt that making changes in their work environment was restricted by managers, behavioral patterns on the job, and the organization culture. In contrast, participants of the same job crafting training who reported that they perceived opportunities to craft their job successfully made changes to their work environments. Thus, employees' work environment may directly influence their job crafting behavior. For example, managers who give their employees (positive) feedback on their job crafting actions may positively affect the latter's perceived opportunities to craft (see also Wrzesniewski, 2003). If we take a closer look at this example, employees' perceived opportunities to craft may be predicted by job resources. This idea is in line with the findings of a study by van Wingerden \& Niks (2017), which revealed that perceived opportunities to craft and job resources (autonomy and opportunities for professional development) are positively interrelated yet distinctive constructs. Job demands may also have an impact on employees' perceived opportunities to craft. For example, employees who experience a highly demanding work environment may need to use all their energy for completing their task and may see fewer opportunities to initiate proactive changes in their job. Thus, we propose a positive relationship between employees' job resources and perceived opportunities to craft, and a negative relationship between employees' job demands and perceived opportunities to craft. We therefore hypothesize:

Hypothesis 1: Employees' job resources, role clarity, communication and teamcohesion are positively related to their perceived opportunities to craft.

Hypothesis 2: Employees' job demands, workload, emotional demands and work- home interference are negatively related to their perceived opportunities to craft.

Further, besides the influence of job demands and job resources on employees' perceived opportunities to craft, research revealed that in turn, perceived opportunity to craft itself may 


\section{Macrothink}

International Journal of Human Resource Studies

ISSN 2162-3058

2018, Vol. 8, No. 4

influence employees' actual job crafting behavior (van Wingerden \& Niks, 2017; van Wingerden \& Poell, 2017). Thus, our theoretical arguments suggest that the relationship between job characteristics and job crafting behavior may be mediated via perceived opportunities to craft. We therefore hypothesize:

Hypothesis 3: Employees' job resources, (role clarity, communication and team cohesion) have a positive relationship with job crafting and this relationship is mediated by their perceived opportunities to craft.

Hypothesis 4: Employees' job demands, (workload, emotional demands and work-home interference) have a negative relationship with job crafting and this relationship is mediated by their perceived opportunities to craft.

With these four hypotheses together, we propose and aim to test the antecedents of job crafting perceptions and behavior model (see Figure 1).

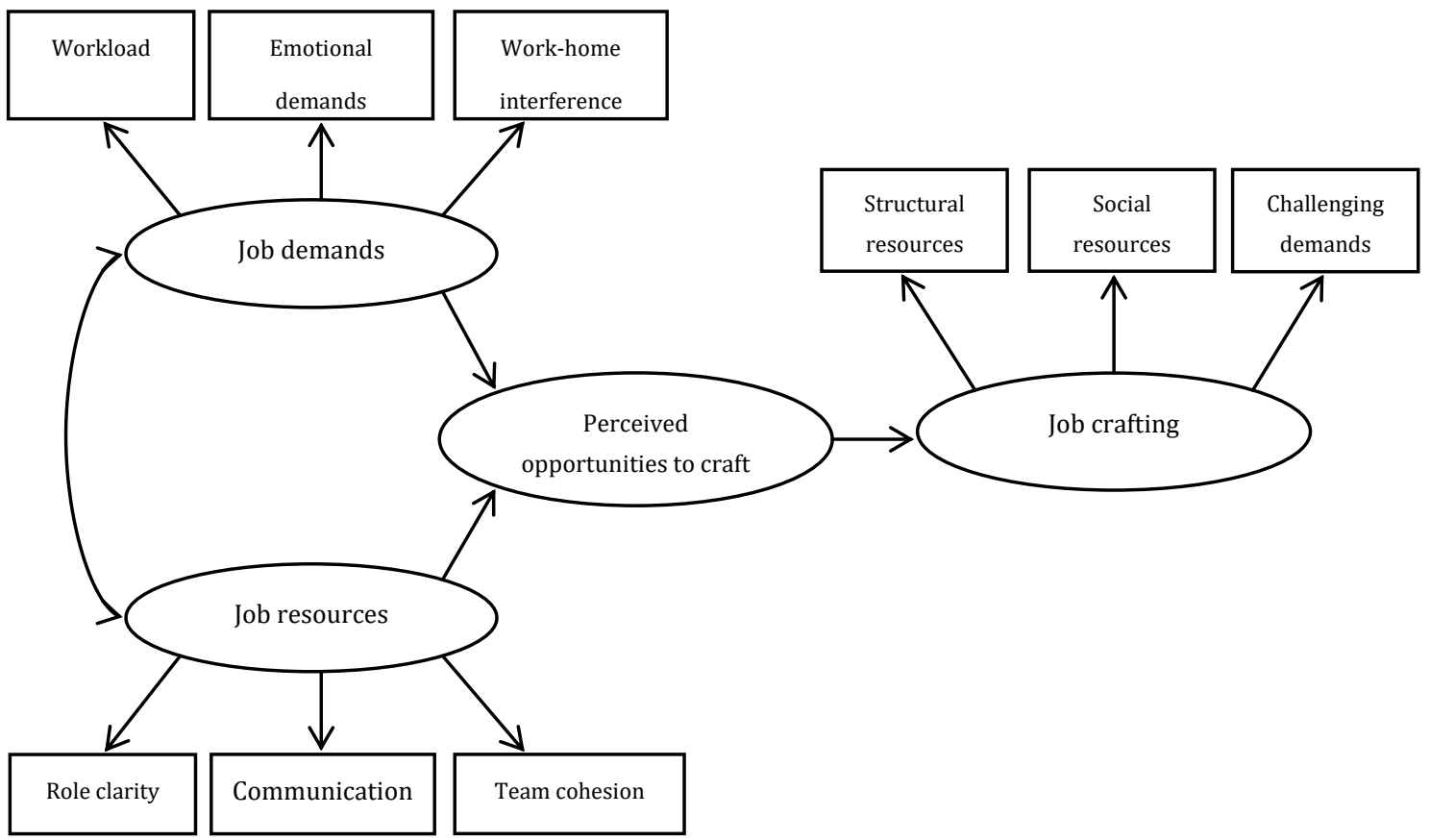

Figure 1. The Proposed Model

\section{Method}

\subsection{Participants and Procedure}

The sample consisted of 491 female (94\%) and 31 male health care professionals $(6 \%)$ who diagnose, identify and treat patients with mental disabilities. This gender skewed distribution is representative for the occupational group, in which more women than men are employed (Merens, Hartgers, \& van den Brakel, 2012). The mean age of the participants was 40 years $(S D=10.28)$, and $84 \%$ had successfully finished a higher vocational education or university degree in health care. Respondents were invited to participate on a voluntary basis and directed to the survey through an online link. The survey was available for 3 weeks and the organization allowed their employees to fill in the questionnaires during their workday. Data 
was collected in accordance with the ethical guidelines of the Dutch Association of Psychologists and of the American Psychological Association. In line with the ethical guidelines, participation was completely voluntary, data collection through a self-report survey was exempted from an institutional ethics committee's approval, and the respondents did not receive any compensation for their contribution. Informed consent was given by clicking on the "Finish" button at the end of the survey.

\subsection{Measures}

Job Demands. Workload was measured using a three-item Dutch version (Furda, 1995) of Karasek's (1985) job content instrument. A sample item is: "Do you have to work quickly?" Emotional demands were assessed with a shortened three-item version (emotional demands) of the scale developed by van Veldhoven and Meijman (1994). An example of an emotional demands item is, "Does your work put you in emotional situations?". Work-home interference was measured using the SWING scale by Geurts et al., (2005). A sample item is: "How often does it occur that you have trouble keeping your attention focussed on your work, because you worry about your home situation?" All items were scored on a five-point scale ranging from (1) never to (5) always.

Job Resources. Role Clarity was measured using six items from the foundational work of Rizzo et al. (1970). A sample item is: "In my work, I know exactly what is expected of me". Team Cohesion was measured using the team cohesion questionnaire by Chang and Bordia (2001). A sample item is: "Everyone tries to help if team members have problems." Items for both measures were scored on a seven-point scale ranging from (1) strongly disagree to (7) strongly agree. Communication. The communication measure in this study was derived from the Questionnaire on the Experience and Evaluation of Work (VBBA; cf. van Veldhoven \& Broersen, 1999). A sample item is: "The provision of information from management to employees is sufficient". These items were scored on a five-point scale ranging from (1) strongly disagree to (5) strongly agree.

Perceived opportunity to craft (POC) was measured using the five-item scale developed by van Wingerden and Niks (2017). An example is: "At work I have the opportunity to take on new activities and challenges". Participants had to score the items on a 7-point scale ranging from 1 (totally disagree) to 7 (totally agree).

Job crafting was measured using 3 subscales of the job crafting questionnaire developed by Tims et al. (2012). From each subscale, four items were included and scored on a five-point scale ranging from 1 (never) to 5 (very often). Examples are: "I ask colleagues for advice" (increasing social job resources), "I regularly take on extra tasks even though I do not receive extra salary for them" (increasing challenging job demands), and "I try to learn new things at work" (increasing structural job resources).

\subsection{Analysis}

The antecedents of job crafting perception and behavior model (see Figure 1) was tested with structural equation modelling (SEM) analyses using the AMOS software package (Arbuckle, 2005). In order to assess the fit of the measurement model and the alternative models to the 
data, the chi-square, the goodness-of-fit index (GFI), and the root mean square error of approximation (RMSEA) were tested. In addition, the incremental fit index (IFI), and the comparative fit index (CFI) were also assessed as recommended by Marsh, Balla, and Hau (1996). The values of GFI, IFI, CFI $>.90$ and RMSEA $<.08$ indicate a reasonable fit of the model to the data (Browne and Cudeck, 1993; Hoyle, 1995). The use of parcels in testing structural equation modelling results in more reliable measurement models (Little, Cunningham, Shahar, \& Widaman, 2002). We therefore conducted our SEM analysis on a partial disaggregation model (Bagozzi \& Edwards, 1998) by creating parcels of items as also recommended by Hall, Snell, and Foust (1999). Parcels of items were created for the variable 'Perceived opportunity to craft', which were included in the model as latent factors with two indicators. 'Job demands', 'Job resources' and 'Job crafting' were included as latent factors with their abovementioned subscales as the indicators. We examined whether significant pathways between job characteristics and job crafting represented indirect relationships by means of bootstrapping.

\section{Results}

\subsection{Descriptive Statistics}

A summary of the descriptive statistics for all the main variables, including means, standard deviations, correlations, and reliability estimates (Chronbach's alpha) is displayed in Table 1. Prior to testing the proposed model, we first tested a measurement model with SPSS AMOS to verify that our latent variables were accurately measured by their parcels. The results revealed that that the measurement model had a good fit with the data, $\chi^{2}(38)=83.252, p$ $<.001 ; \mathrm{CFI}=.977 ; \mathrm{TLI}=.966 ; \mathrm{IFI}=.977 ; \mathrm{RMSEA}=.048$ (see Table 2 for an overview of all tested models). In addition, both parcels had significant loadings on the intended factors (range $\lambda=.57-.92 ; p<.001$ ).

Table 1 Summary of the Descriptive Statistics for all the Main Variables, Including Means, Standard Deviations, Correlations, and Reliability Estimates (Chronbach's Alpha, Diagonal).

\begin{tabular}{|c|c|c|c|c|c|c|c|c|c|c|c|c|c|}
\hline & & $\bar{M}$ & $S D$ & 1 & 2 & 3 & 4 & 5 & 6 & 7 & 8 & 9 & 10 \\
\hline 1 & Workload & 2.81 & 0.92 & $(.88)$ & & & & & & & & & \\
\hline 2 & Emotional demands & 1.79 & 0.49 & $.37^{* *}$ & (.69) & & & & & & & & \\
\hline 3 & Work-home interference & 1.87 & 0.70 & $.51^{* *}$ & $.43^{* *}$ & $(.76)$ & & & & & & & \\
\hline 4 & Role clarity & 3.63 & 0.57 & $-.17^{* *}$ & $-.26^{* *}$ & $-.29^{* * *}$ & $(.74)$ & & & & & & \\
\hline 5 & Communication & 3.07 & 0.63 & $-.09^{*}$ & $-.21^{* *}$ & $-.24^{* * *}$ & $.60^{* *}$ & (.75) & & & & & \\
\hline 6 & Team cohesion & 3.86 & 0.65 & $-.17^{* *}$ & $-.29^{* *}$ & $-.32^{* *}$ & $.53^{* *}$ & $.49^{* *}$ & $(.74)$ & & & & \\
\hline 7 & Perceived opportunities to craft & 5.32 & 0.91 & $-.10^{*}$ & $-.17^{* *}$ & $-.23^{* * *}$ & $.39^{* *}$ & $.35^{* *}$ & $.33^{* *}$ & $(.88)$ & & & \\
\hline 8 & JC: Structural resources & 4.09 & 0.52 & .07 & -.07 & $-.12^{* *}$ & $.23^{* *}$ & $.20^{* *}$ & $.18^{* *}$ & $.37^{* *}$ & (.67) & & \\
\hline 9 & JC: Social resources & 3.67 & 0.66 & .08 & .06 & .02 & $.16^{* *}$ & $.17^{* *}$ & $.15^{* *}$ & $.25^{* *}$ & $.45^{* *}$ & (.77) & \\
\hline 10 & JC: Challenging demands & 3.47 & 0.73 & $10^{*}$ & .02 & .02 & $.13^{* *}$ & $.15^{* *}$ & .06 & $.24^{* *}$ & $.52^{* *}$ & $.50^{* * *}$ & (.74) \\
\hline
\end{tabular}


Table 2. Fit Indices for all Models Tested in the Study

\begin{tabular}{llllllll}
\hline Model & $\chi^{2}$ & $d f$ & $p$ & CFI & TLI & IFI & RMSEA \\
\hline Measurement model & 83.252 & 38 & $<.001$ & .971 & .966 & .971 & .048 \\
Proposed model & 132.292 & 40 & $<.001$ & .971 & .945 & .971 & .052 \\
First alternative model & 191.655 & 40 & $<.001$ & .922 & .892 & .922 & .085 \\
Second alternative model & 160.122 & 40 & $<.001$ & .938 & .915 & .939 & .076 \\
Direct effects model & 259.532 & 41 & $<.001$ & .887 & .849 & .888 & .101 \\
\hline
\end{tabular}

\subsection{Hypothesis Testing}

To test whether or not our proposed model fit the data, we used SPSS AMOS to conduct a path analysis. The results showed that the proposed model had a good fit with the data, $\chi^{2}(40)$ $=95.857, \mathrm{p}<.001 ; \mathrm{CFI}=.971 ; \mathrm{TLI}=.960 ; \mathrm{IFI}=.971 ; \mathrm{RMSEA}=.052$. The coefficients of the relationships are summarized in Figure 2. Job demands and job resources were negatively related to one another $(\beta=-.45, \mathrm{p} .001)$. There was no relationship between job demands and perceived opportunities to craft $(\beta=-.04, p=.526)$, but job resources did have a positive relationship with perceived opportunities to craft $(\beta=.50, \mathrm{p}<.001)$. Perceived opportunities to craft, in turn, was positively related to job crafting behavior $(\beta=.43, p<.001)$. We also tested the indirect effect with perceived opportunity to craft as a mediating variable by using the bootstrap analysis option in AMOS (MacKinnon, 2008), with bias-corrected 95\% confidence intervals. There was no indirect effect between job demands and job crafting ( $\beta=$ $-.02 ; 95 \% \mathrm{CI}-.73, .43 ; \mathrm{p}=.515)$. However, there was a significant positive indirect effect between job resources and job crafting $(\beta=.22 ; 95 \% \mathrm{CI} .14, .32, \mathrm{p}=.007)$.

According to the JD-R approach of job crafting (Tims et al., 2012), employees can also proactively adapt their job demands and job resources via job crafting. Therefore we tested an alternative model as well, in which job crafting simultaneously predicted job demands and job resources, and both subsequently predicting perceived opportunities to craft. In other words: Job crafting was moved from the end of the model to the beginning of the model. This alternative model showed a poor fit to the data, $\chi^{2}(40)=191.655, \mathrm{p}<.001 ; \mathrm{CFI}=.922$; TLI $=.892 ; \mathrm{IFI}=.922, \mathrm{RMSEA}=.085$. Because the degrees of freedom of the alternative model were equal to those of the proposed model, chi-square difference testing was not possible. Therefore, we instead compared the AIC indices to determine which model had the best fit. Since the proposed model (AIC $=147.857$ ) had a lower AIC value than the alternative model $(\mathrm{AIC}=243.655)$, the proposed model was deemed preferable. We then tested a second alternative model that was similar to the proposed model but had the positions of POC and job crafting switched with one another. In other words, job demands and job resources simultaneously predicted job crafting, which in turn predicted POC. This model showed an acceptable fit to the data, $\chi^{2}(40)=160.122, \mathrm{p}<.001$; CFI $=.938$; TLI $=.915$; IFI $=.939$, RMSEA $=.076$. However, this model's AIC value $(\mathrm{AIC}=212.122)$ was considerably higher than that of the proposed model $($ AIC $=147.857)$. Thus, the proposed model was still the preferred model. 


\section{Macrothink}

International Journal of Human Resource Studies

ISSN 2162-3058

2018, Vol. 8, No. 4

Lastly, we also tested a direct effects model where job crafting was directly predicted by job demands, job resources, and POC. This model showed a poor fit to the data, $\chi^{2}(41)=259.532$, $\mathrm{p}<.001 ; \mathrm{CFI}=.887$; TLI $=.849 ; \mathrm{IFI}=.888 ; \mathrm{RMSEA}=.101$. The model fit of the direct effects model was also significantly worse than the fit of the proposed model, $\Delta \chi^{2}(1)=$ $163.675, \mathrm{p}<.001$. Hence, the outcomes of the analyses showed that hypotheses 1 and 3 were confirmed but hypotheses 2 and 4 were rejected. Thus, these findings offer partial support for our hypothesized antecedents of job crafting perceptions and behavior model.

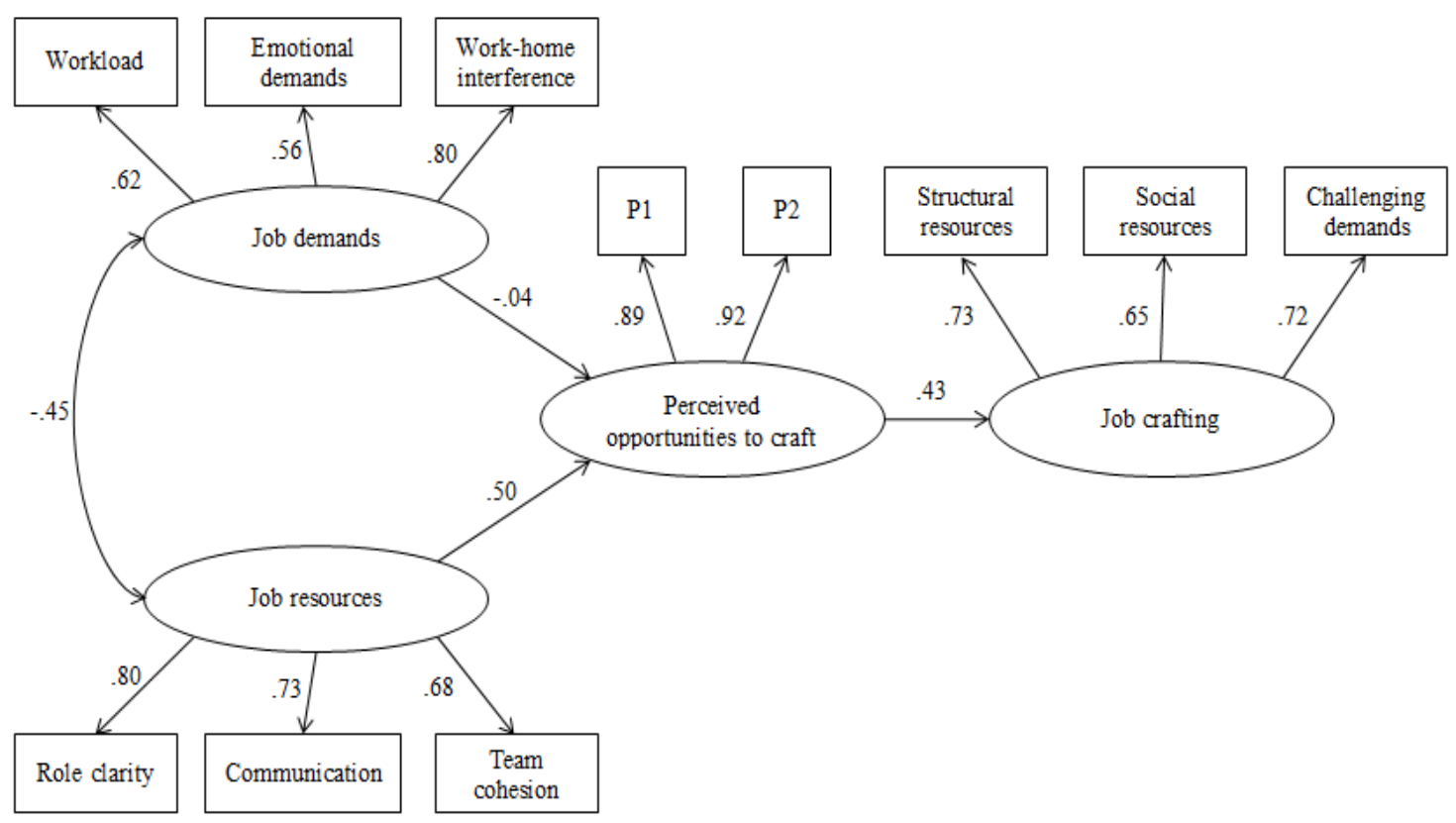

Figure 2. Final Results of the Proposed Model. Including Standardized Coefficients for all Relations

\section{Discussion}

In this paper, we have argued that employees' perceived opportunities to craft mediate the relationship between job demands / resources and employees' actual job crafting behavior. Although previous research revealed that job crafting can be beneficial for both employees and employers (Leana, Appelbaum, \& Shevchuk, 2009; Petrou, et al., 2012; van Wingerden, Bakker, \& Derks, 2017a), up till now little was known about how job characteristics influence job crafting perceptions, and subsequently job crafting behaviors. The results of our study partially supported the proposed antecedents of job crafting perceptions and behavior model. Employees' job resources turned out to be antecedents of employees' perceived opportunities to craft, which in turn was found to be an antecedent of employees' actual job crafting behavior. However, no relationship was found between job demands and job crafting behavior. Thus, this study showed that job resources in the work environment, play an important role in employees' perceptions of the opportunities they have to make self-initiated changes aimed at aligning their job (and work environments) with their own preferences, motives, and passions. In the next section, we discuss the contributions of our study. 


\subsection{Theoretical Contributions}

A first contribution of this article is that it offers evidence for the relationships between employees' job characteristics and employees' perceived opportunities to craft. Literature suggests that employees' perceived opportunities to craft and their actual job crafting behavior may depend on their job characteristics (van Wingerden \& Niks, 2017; van Wingerden \& Poell, 2017; Wrzesniewski, 2003), however until now no study had empirically examined this proposed relationship. As the outcomes of this study reveal, job resources (role clarity, communication and team cohesion) are important antecedents of employees' perceived opportunities to craft, unlike job demands (workload, emotional demands and work-home interference). These findings related to job demands are in line with earlier studies that showed that the relationships between job demands and job crafting behavior were negative and/or non-significant (Leana et al., 2009; van Wingerden, Bakker, \& Derks, 2017a). This study revealed that job resources are not just aspects of the job that help employees to achieve their work goals and buffer the effects of job demands (Demerouti et al., 2001). Apparently, they also play a role in employees' perceptions of the opportunities to make self-initiated changes at work to align their job with their own preferences, talents and passions. Or as we can state from a Broaden-and-Build theory (Fredrickson, 2001; Fredrickson \& Branigan, 2005) perspective, the experience of job resources broadened employees' attention, cognition action repertoires (including their perceptions of opportunities to craft their job), and actual job crafting behavior. Further, in line with the Conservation of Resources theory (Hobfoll, 1989), the findings of this study showed that employees who experience role clarity, team cohesion and clear communication, see opportunities to maintain their resources and pro-actively try to conserve them.

Further, this study builds on job crafting literature by showing that employees' perceived opportunities to craft mediate the relationship between job resources and actual job crafting behavior. These insights are helpful to understand which aspects of the workplace influence whether or not employees will craft their job. The empirical findings of this study are in line with the job crafting framework presented by Wrzesnewski and Dutton (2001). The present study is one of the first to empirically test the perception / behavior relationship of the job crafting framework. These insights may help researchers to shed a light on the dynamic relationships between the contemporary work environment and job crafting perceptions, and subsequently employees' job crafting behaviors. Viewed this way, the current study has a contribution beyond the research on job crafting and adds to Job Demands-Resources Theory (Bakker \& Demerouti, 2014) as well. In JD-R theory, job crafting has been acknowledged as an important bottom-up strategy to optimize job demands and resources in the workplace. Our study shed a light on how the work environment and perceived opportunities to craft play a role in employees' pro-active behavior to optimize their job demands and resources. 


\subsection{Limitations and Suggestions for Future Research}

Although this study provides partial evidence for the proposed antecedents of job crafting perceptions and behavior model, there are also limitations of our study that need to be mentioned. One limitation of this study concerns the study sample. The sample consisted of Dutch health care professionals only, which restricts the generalizability of our findings. Future studies should try to replicate our study in different sectors among employees of several other occupational groups on different continents. In a similar vein, the job demands and job resources measures chosen in this study are relevant especially for health care employees (Atefin, Abdullah, Wong, \& Mazlom, 2014; Gaillard, 2006; Nei, Snyder, \& Litwiller, 2015; Simpson, 2009; Valentine et al., 2015). Other job demands and job resources that we did not measure may be more suitable for other sectors or industries. We encourage future studies to replicate our findings and to include more and different job demands and job resources, especially since we did not find support for the proposed relationship between job demands and job crafting in this study.

A second limitation is the self-report nature of our data. By using self-reports, we cannot entirely avoid the risk of common method bias, which may inflate the correlations between the variables. However, employees' evaluations of their job and work experience may be subjective, and self-reports may be the best method to measure these perceptions and feelings (Sousa-Poza \& Sousa-Poza, 2000). Although this study fundamentally depends on employee perceptions, the chosen methods are prone to self-report bias, and therefore the results should be interpreted with caution. Future research might also explore other, more objective ways to measure this study's main variables (e.g., Podsakoff, MacKenzie, Lee, \& Podsakoff, 2003), for example, via other ratings of job crafting behavior provided by supervisors and/or colleagues.

A third limitation of this study is that we cannot warrant causality in our study design since predictor, mediator and outcome variables were not temporally separated. Future research should try to replicate our study using a longitudinal design or diary study design to examine the causal relationships among the variables. Finally, this study focused specifically on job demands and job resources as antecedents of perceived opportunities to craft. Future studies should also examine other possible antecedents of perceived opportunities to craft, such as organizational climate and/or leadership. Besides examining other possible antecedents, future studies may also include different types of control variables, such as self-efficacy or optimism.

\subsection{Practical Implications and Conclusion}

A practical implication of the findings of this study is that organizations should be aware of the influence of job resources on employees' perceived opportunities to craft, and subsequently their actual job crafting behavior. Organizations that want to stimulate employees' proactive change behavior should facilitate their employees with a resourceful work environment. In offering a resourceful work environment, both organizational and individual aspects are important to take into account. In addition, the cultivation of a resourceful work environment that stimulates job crafting behavior is an important task for 
both management and HR. As a start, organizations should design jobs that yield supportive features for employees. In a similar vein, HR policies and practices, such as the annual performance management process and career development programs, may strengthen employees' experience of a resourceful work environment, when employees' needs for job resources are part of the design of these policies and practices.

To understand employees' needs in relation to their job resources, organizations can use surveys to find out whether employees experience they have an adequate amount of resources in their work environment, and if these resources are the ones that are helpful in their daily work. In addition, organizations can also use surveys to examine to which extent employees perceive opportunities to craft their job and engage in actual job crafting behavior. Understanding employees' needs and work experience may be a starting point to optimize these conditions. Besides the influence of job design and HR practices and policies, managers may influence employees' job crafting by their daily behavior in the workplace. For example, by clearly communicating the goals and the expected contributions of each employee (role clarity), by stimulating collaboration within and among teams and by enhancing a sense of belonging (team cohesion). Further, managers can share positive examples of their own job crafting behavior in the workplace or they can share positive job crafting experiences within teams. By sharing these examples, managers show their support for employees' job crafting behaviors, which may positively influence employees' perceived opportunities to craft. In addition, examples of managers' own job crafting behavior may also be a source of inspiration for their employees. As mentioned above, future research may examine this proposed positive relationship of leadership behavior with perceived opportunities to craft and job crafting behavior. In conclusion, this study provides insights into the unique role of perceived opportunities to craft. It demonstrates that perceived opportunities to craft may operate as a mediator between employees' resources in their work context and their actual job crafting behavior. Several studies underline the benefits of job crafting behavior for both employees and employers (van Wingerden, Bakker, \& Derks, 2017a; van Wingerden, Bakker, \& Derks, 2017b; Wellman \& Spreitzer, 2011; Wrzesniewski, LoBuglio, Dutton, \& Berg, 2013). Due to all these merits, we strongly advocate the deliberate cultivation of job crafting behavior within organizations. Therefore, we hope that our study will motivate other researchers to further explore the job crafting perceptions / behavior relationship in order to increase employee well-being within contemporary organizations.

\section{Funding}

This research received no specific grant from any organization or funding agency.

\section{References}

Akkermans, J., \& Tims, M. (2017). Crafting your career: How career competencies relate to career success via job crafting. Applied Psychology, 66, 168-195. https://doi.org/10.1111/apps.12082

Arbuckle, J. L. (2005). Amos 6.0 User's Guide. Chicago, IL: SPSS, Inc. 
Atefi, N., Abdullah, K. L., Wong, L. P. \& Mazlom, R. (2014) Factors influencing registered nurses perception of their overall job satisfaction: a qualitative study. International Nursing Review 61, 352-360. https://doi.org/10.1111/inr.12112

Bagozzi, R. P., \& Edwards, J. R. (1998). A general approach for representing constructs in organizational research. Organizational Research Methods, 1, 45-87. https://doi.org/10.1177/109442819800100104

Bakker, A. B., \& Demerouti, E. (2014). Job demands-resources theory. In C. Cooper and P. Chen (Eds.), Wellbeing: A complete reference guide (pp. 37-64). Chichester, UK: Wiley-Blackwell.

Bakker, A. B., Tims, M., \& Derks, D. (2012). Proactive personality and job performance: The role of job crafting and work engagement. Human Relations, 65, 1359-1378. https://doi.org/10.1177/0018726712453471

Beal, D. J., Cohen, R. R., Burke, M. J., \& McLendon, C. L. (2003). Cohesion and performance in groups: A meta-analytic clarification of construct relations. Journal of Applied Psychology, 88, 989-1004. https://doi.org/10.1037/0021-9010.88.6.989

Bennett, N., \& Lemoine, G. J. (2014). What a difference a word makes: Understanding threats to performance in a VUCA world. Business Horizons, 57, 311-317. https://doi.org/10.1016/j.bushor.2014.01.001

Berg, J. M., Wrzesniewski, A., \& Dutton, J. E. (2010). Perceiving and responding to challenges in job crafting at different ranks: When proactivity requires adaptivity. Journal of Organizational Behavior, 31, 158-186. https://doi.org/10.1002/job.645

Browne, M. W., \& Cudeck, R. (1993). Alternative ways of assessing model fit. In K.A. Bollen and J. S. Long (Eds.), Testing structural equation models (pp. 445-455). Newbury Park, CA: Sage. https://doi.org/10.1177/0049124192021002005

Cenciotti, R., Alessandri, G., \& Borgogni, L. (2017). Psychological capital and career success over time: The mediating role of job crafting. Journal of Leadership \& Organizational Studies, 24, 372-384. https://doi.org/10.1177/1548051816680558

Chang, A., \& Bordia, P. (2001). A multidimensional approach to the group cohesion-group performance relationship. Small Group Research, 32, 379-405. https://doi.org/10.1177/104649640103200401

Cooke, F., \& Bartram, T. (2015). Guest Editors' Introduction: Human Resource Management in health care and elderly care: current challenges and toward a research agenda. Human Resource Management, 54(5), 711-735. https://doi.org/10.1002/hrm.21742

Demerouti, E., Bakker, A. B., \& Gevers, J. M. (2015). Job crafting and extra-role behavior: The role of work engagement and flourishing. Journal of Vocational Behavior, 91, 87-96. https://doi.org/10.1016/j.jvb.2015.09.001 
Demerouti, E., Bakker, A. B., Nachreiner, F., \& Schaufeli, W. B. (2001). The job demands-resources model of burnout. Journal of Applied psychology, 86(3), 499. https://doi.org/10.1037/0021-9010.86.3.499

Frederickson, B. L., \& Branigan, C. (2005). Positive emotions broaden the scope of attention and thought-action repertoires. Cognition \& Emotion, 19, 313-332. https://doi.org/10.1080/02699930441000238

Fredrickson, B. L. (2001). The role of positive emotions in positive psychology: The broaden-and-build theory of positive emotions. American Psychologist, 56, 218-226. https://doi.org/10.1037/0003-066X.56.3.218

French, F., Ikenwilo, D., \& Scott, A. (2007). What influences the job satisfactions of staff and associate specialist hospital doctors. Health Services Management Research, 20, 153-161. https://doi.org/10.1258/095148407781395982

Furda, J. (1995). Werk, persoon en welzijn: Een toets van het JD-C model. [Work, personality, and wellbeing: A test of the JD-C model]. Unpublished doctoral dissertation, Utrecht University, The Netherlands.

Gaillard, A. (2006). Stress, productiviteit en gezondheid [Stress, productivity and health]. Amsterdam: Uitgeverij Nieuwezijds.

Geurts, S. A., Taris, T. W., Kompier, M. A., Dikkers, J. S., van Hooff, M. L., \& Kinnunen, U. M. (2005). Work-home interaction from a work psychological perspective: Development and validation of a new questionnaire, the SWING. Work \& Stress, 19, 319-339. https://doi.org/10.1080/02678370500410208

Ghitulescu, B. E. (2007). Shaping tasks and relationships at work: Examining the antecedents and consequences of employee job crafting. Unpublished doctoral dissertation, University of Pittsburgh, PA, USA.

Grant, A. M., \& Parker, S. K. (2009). Redesigning work design theories: The rise of relational and proactive perspectives. Academy of Management Annals, 3, 317-375. https://doi.org/10.5465/19416520903047327

Hall, R. J., Snell, A. F., \& Foust M. (1999). Item parceling strategies in SEM: Investigating the subtle effects of unmodeled secondary constructs. Organizational Research Methods, 2, 233-256. https://doi.org/10.1177/109442819923002

Hobfoll, S. E. (1989). Conservation of resources: A new attempt at conceptualizing stress. American Psychologist, 44, 513-524. https://doi.org/10.1037/0003-066X.44.3.513

Hobman, E. V., Bordia, P., \& Gallois, C. (2004). Perceived dissimilarity and work group involvement: The moderating effects of group openness to diversity. Group \& Organization Management, 29, 560-587. https://doi.org/10.1177/1059601103254269 
Homburg, V., van der Heijden, B., \& Valkenburg, L. (2013) Why do nurses change jobs? An empirical study on determinants of specific nurses' post-exit destinations. Journal of Nursing Management 21, 817-826. https://doi.org/10.1111/jonm.12142

Hoyle, R. H. (1995). Structural equation modeling: Concepts, issues, and applications. Thousand Oaks, CA: Sage.

Karasek, R. (1985). Job content instrument: Questionnaire and user's guide, revision 1.1 Los Angeles: University of Southern California.

Leana, C., Appelbaum, E., \& Shevchuk, I. (2009). Work process and quality of care in early childhood education: The role of job crafting. Academy of Management Journal, 52, 1169-1192. https://doi.org/10.5465/amj.2009.47084651

LePine, J. A., \& Van Dyne, L. (1998). Helping and Voice Extra-Role Behaviors: Evidence of Construct and Predictive Validity. The Academy of Management Journal, 41(1), 108-119.

Little, T. D., Cunningham, W. A., Shahar, G., \& Widaman, K. F. (2002). To parcel or not to parcel: Exploring the question, weighing the merits. Structural Equation Modeling, 9, 151-173. https://doi.org/10.1207/S15328007SEM0902_1

Lusky, R., \& Ingman, S. (1994). Medical care in residential settings: The nursing home in transition. In E. Folts \& D. Yeatts (Eds.), Housing and the aging population: Options for the new century (pp. 261-284). New York: Routledge.

Lyons, P. (2008). The crafting of jobs and individual differences. Journal of Business Psychology, 23, 25-36. https://doi.org/10.1007/s10869-008-9080-2

MacKinnon, D. P. (2008). Introduction to statistical mediation analysis. New York: Routledge.

Marsh, H. W., Balla, J. R., \& Hau, K. T. (1996). An evaluation of Incremental Fit Indices: A clarification of mathematical and empirical properties. In G. A. Marcoulides \& R. E. Schumacker (Eds.), Advanced structural equation modeling: Issues and techniques (pp. 315-353). Mahwah, NJ: Lawrence Erlbaum Associates.

Mathieu, J., Maynard, T., Rapp, T., \& Gilson, L. (2008). Team effectiveness 1997-2007: A review of recent advancements and a glimpse into the future. Journal of Management, 34, 410-476. https://doi.org/10.1177/0149206308316061

Merens, A., Hartgers, M., \& van den Brakel, M. (2012). Emancipatiemonitor 2012 [Emancipation monitor]. The Hague: CBS. Retrieved from http://www.cbs.nl/NR/rdonlyres/F5DF2565-1721-40A4-BF16-FF7852AAC53D/0/emancipati emonitor2012.pdf (accessed 12 September 2014).

Molleman, E., Nauta, A., \& Jehn, K. A. (2004). Person-job fit applied to teamwork: A multilevel approach. Small Group Research, 35, 515-539. https://doi.org/10.1177/1046496404264361 


\section{MInstitute ${ }_{\text {Mnk }}^{\text {Macrothink }}$}

International Journal of Human Resource Studies

ISSN 2162-3058

2018, Vol. 8, No. 4

Nei, D., Snyder, L. A., \& Litwiller, B. J. (2015). Promoting retention of nurses: A meta-analytic examination of causes of nurse turnover. Health care management review, 40, 237-253. https://doi.org/10.1097/HMR.0000000000000025

Petrou, P., Demerouti, E., Peeters, M. C. W., Schaufeli, W. B., \& Hetland, J. (2012). Crafting a job on a daily basis: Contextual correlates and the link to work engagement. Journal of Organizational Behavior, 33, 1120-1141. https://doi.org/10.1002/job.1783

Podsakoff, P. M., MacKenzie, S. B., Lee., J., \& Podsakoff, N. P. (2003). Common method bias in behavioral research: A critical review of the literature and recommended remedies. Journal of Applied Psychology, 88, 879-903. https://doi.org/10.1037/0021-9010.88.5.879

Randall, G. E. \& Williams, A. P. (2006). Exploring limits to market-based reform: Managed competition and rehabilitation home care services in Ontario. Social Science \& Medicine, 62, 1594-1604. https://doi.org/10.1016/j.socscimed.2005.08.042

Rijckmans, M., Garretsen, H., van den Goor, I., \& Bongers, I. (2006). Demand-oriented and demand driven health care: The development of a typology. Scandinavian Journal of Caring Sciences, 21, 406-416. https://doi.org/10.1111/j.1471-6712.2007.00476.x

Rizzo, J. R., House, R. J., \& Lirtzman, S. I. (1970). Role conflict and ambiguity in complex organizations. Administrative Science Quarterly, 15, 150-163. https://doi.org/10.2307/2391486

Simpson, M. R. (2009). Predictors of work engagement among medical-surgical registered nurses. Western Journal of Nursing Research, 31, 44-65. https://doi.org/10.1177/0193945908319993

Slemp, G. R., \& Vella-Brodrick, D. A. (2014). Optimising employee mental health: The relationship between intrinsic need satisfaction, job crafting, and employee well-being. Journal of Happiness Studies, 15, 957-977. https://doi.org/10.1007/s10902-013-9458-3

Sousa-Poza, A., \& Sousa-Poza, A. A. (2000). Well-being at work: A cross-sectional study of the levels and determinants of job satisfaction. Journal of Socio-Economics, 29, 517-538. https://doi.org/10.1016/S1053-5357(00)00085-8

Tims, M., Bakker, A. B., \& Derks, D. (2012). Development and validation of the job crafting scale. Journal of Vocational Behavior, 80, 173-186. https://doi.org/10.1016/j.jvb.2011.05.009

Tims, M., Bakker, A. B., Derks, D., \& Van Rhenen, W. (2013). Job crafting at the team and individual level: Implications for work engagement and performance. Group and Organization Management, 38, 427-454. https://doi.org/10.1177/1059601113492421

Valentine, M. A., Nembhard, I. M., \& Edmondson, A. C. (2015). Measuring teamwork in health care settings: A review of survey instruments. Medical Care, 53(4), 16-30. https://doi.org/10.1097/MLR.0b013e31827feef6 
van der Vegt, G. S., Bunderson, S., \& Kuipers, B. (2010). Why turnover matters in self-managing work teams: Learning, social integration and task flexibility. Journal of Management, 26, 1168-1191. https://doi.org/10.1177/0149206309344117

van Stenis, A. R, van Wingerden, J., \& van Kolkhuis, T. I. (2017). The changing role of health care professionals in nursing homes: A literature review of a decade of change. Frontiers in Psychology, 8, 2008.

Van Veldhoven, M. J. P. M., \& Meijman, T. F. (1994). Het meten van psychosociale arbeidsbelasting met een vragenlijst: De vragenlijst beleving en beoordeling van de arbeid [The measurement of psychosocial strain at work: the questionnaire experience and evaluation of work]. Amsterdam: NIA.

van Veldhoven, M., \& Broersen, J. P. J. (1999). Psychosociale arbeidsbelasting en werkstress in Nederland [Psychosocial job demands and job stress in the Netherlands]. Amsterdam: Stichting Kwaliteitsbevordering Bedrijfsgezondheidszorg.

van Wingerden, J., \& Niks, I. (2017). Construction and validation of the Perceived

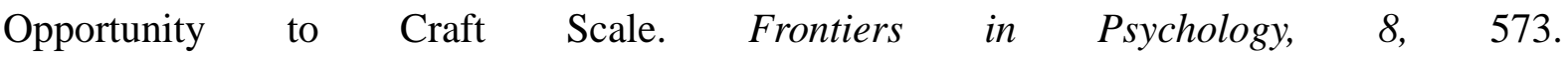
https://doi.org/10.3389/fpsyg.2017.00573

van Wingerden, J., \& Poell, R. F. (2017). Employees' perceived opportunities to craft and in-role performance: The mediating role of job crafting and work engagement. Frontiers in Psychology, 8, 1876. https://doi.org/10.3389/fpsyg.2017.01876

van Wingerden, J., Bakker, A. B., \& Derks, D. (2017a). Fostering employee well-being via a job crafting intervention. Journal of Vocational Behavior, 100, 164-174. https://doi.org/10.1016/j.jvb.2017.03.008

van Wingerden, J., Bakker, A. B., \& Derks, D. (2017b). The longitudinal impact of a job crafting intervention. European Journal of Work and Organizational Psychology, 26, 107-119. https://doi.org/10.1080/1359432X.2016.1224233

van Wingerden, J., Bakker, A. B., \& Derks, D. (2017c). The impact of personal resources and job crafting interventions on work engagement and performance. Human Resource Management, 56, 51-67. https://doi.org/10.1002/hrm.21758

van Wingerden, J., Derks, D., Bakker, A. B., \& Dorenbosch, L. (2013). Job crafting in het speciaal onderwijs: Een kwalitatieve analyse [Job crafting in special education: A qualitative analysis]. Gedrag \& Organisatie, 26, 85-103.

Wageman, R. (2001). How leaders foster self-managing team effectiveness: Design choices $\begin{array}{lllll}\text { versus hands-on } \quad \text { coaching. Organization } & \text { Science, } 12,577 .\end{array}$ https://doi.org/10.1287/orsc.12.5.559.10094

Wellman, N., \& Spreitzer, G. (2011). Crafting scholarly life: Strategies for creating meaning in academic careers. Journal of Organizational Behavior, 32, 927-931. https://doi.org/10.1002/job.708 


\section{Macrothink}

International Journal of Human Resource Studies

ISSN 2162-3058 2018, Vol. 8, No. 4

World Economic Forum (2016). The future of jobs: Employment, skills and workforce strategy for the fourth industrial revolution. Cologny/Geneva: World Economic Forum.

World Economic Forum (2017). Realizing human potential in the fourth industrial revolution: An agenda for leaders to shape the future of education, gender and work. Cologne/Geneva: World Economic Forum.

Wrzesniewski, A. (2003). Finding positive meaning in work. In K. S. Cameron, J. E. Dutton $\&$ R. E. Quinn (Eds.), Positive organizational scholarship: Foundations of a new discipline (pp. 298-308). San Francisco, CA: Berrett-Koehler.

Wrzesniewski, A., \& Dutton, J. E. (2001). Crafting a job: Revisioning employees as active crafters of their work. Academy of Management Review, 26, 179-201. https://doi.org/10.5465/amr.2001.4378011

Wrzesniewski, A., LoBuglio, N., Dutton, J. E., \& Berg, J. M. (2013). Job crafting and cultivating positive meaning and identity in work. Advances in Positive Organizational Psychology, 1, 281-302. https://doi.org/10.1108/S2046-410X(2013)0000001015

Yeatts, D. E., \& Cready, C. M. (2007). Consequences of Empowered CNA Teams in Nursing Home Settings: A Longitudinal Assessment. The Gerontologist, 47, 323-339. https://doi.org/10.1093/geront/47.3.323

Yeatts, D. E., Cready, C., Ray, B., DeWitt, A., \& Queen, C. (2004). Self-managed work teams in nursing homes: Implementing and empowering nurse aide teams. The Gerontologist, 44, 256-261. https://doi.org/10.1093/geront/44.2.256

\section{Copyright Disclaimer}

Copyright for this article is retained by the author(s), with first publication rights granted to the journal.

This is an open-access article distributed under the terms and conditions of the Creative Commons Attribution license (http://creativecommons.org/licenses/by/4.0/) 